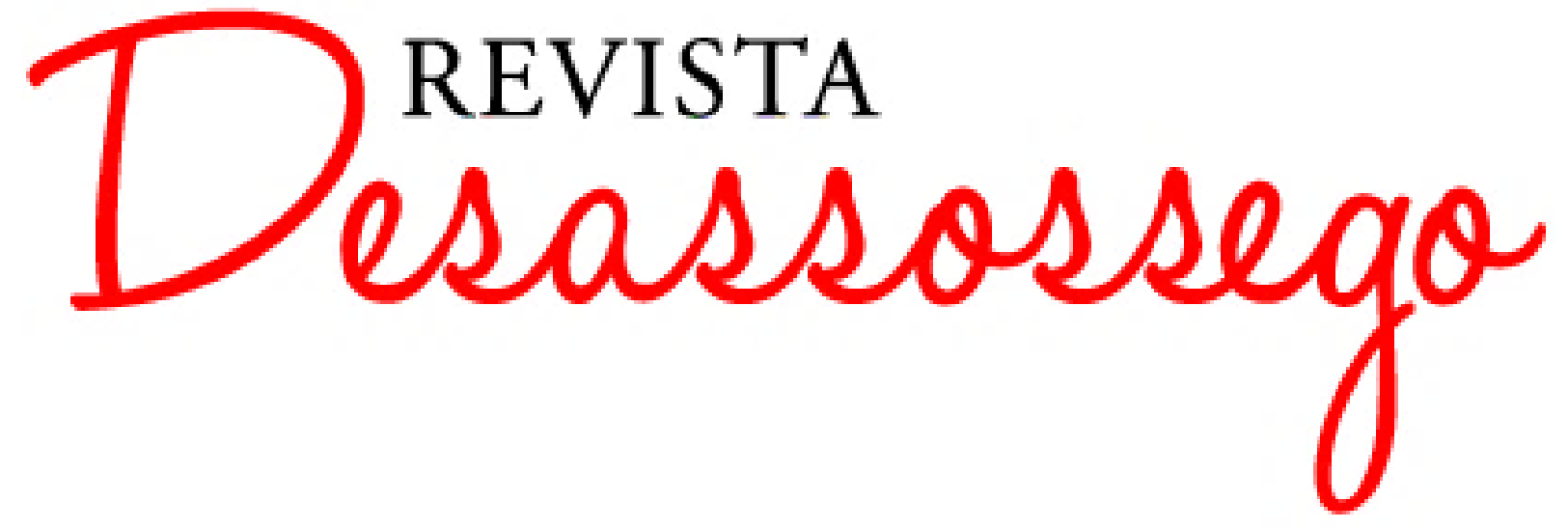




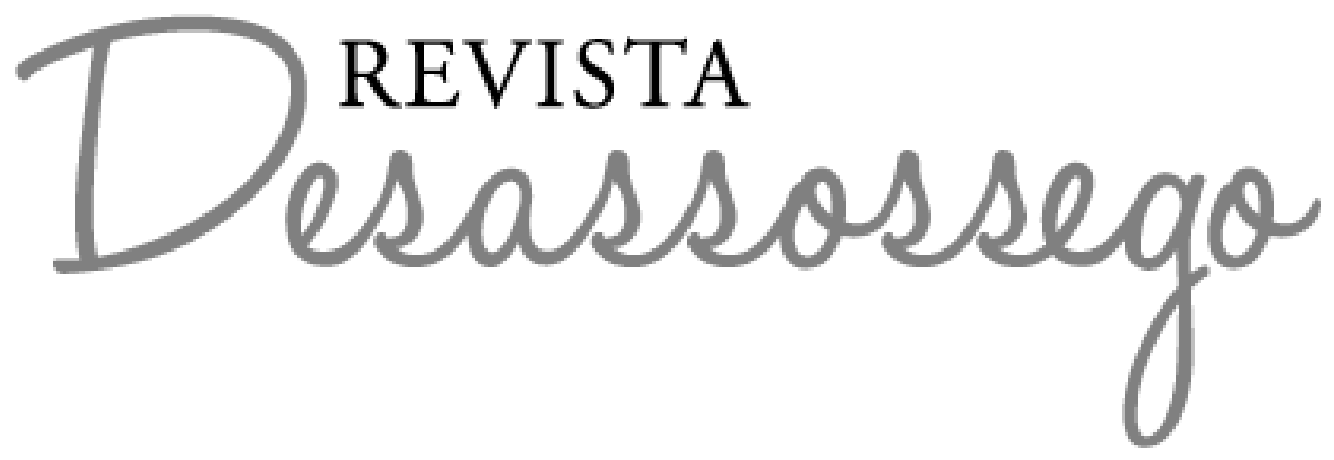

\title{
Literatura Portuguesa e Outras Artes
}

\author{
Bruno Anselmi Matangrano \\ Joana Souto Guimarães Araújo \\ Leonardo de Barros Sasaki \\ (editores-responsáveis)
}


Caros leitores,

Desde suas origens, a literatura dialoga com outras artes, por meio de referências, explícitas ou implícitas, adaptações, citações, imitações, paródias, etc. Já na Grécia Antiga, a poesia muitas vezes era acompanhada pela música, descrevia uma pintura (écfrase) e/ou dava voz às interpretações teatrais. $\mathrm{Na}$ Idade Média, iluminuras decoravam códices e livros de orações, já antevendo a importância da ilustração que, por sua vez, culminaria em formas de arte híbridas, sequenciais, como as histórias em quadrinho. Desde os primórdios do teatro, passando pela dança, pela ópera, pelo cinema, pelos jogos eletrônicos e demais formas multimídias contemporâneas, que nascem justamente da interação entre várias formas artísticas, imagem, movimento e sons se fundem para produzir algo novo, evidenciando a tendência plural da manifestação artística, sobretudo, nas eras moderna e contemporânea. Tendo isso em mente, a Revista Desassossego, em seu $13^{\circ}$ número, preparou o dossiê Literatura Portuguesa e Outras Artes.

O Dossiê se abre com o artigo “'O sonho da razão’: o diálogo interartes e a formação do leitor em Gémeos, de Mário Cláudio”, de Sheila Jacob, no qual a autora explicita as referências do autor português aos quadros do pintor espanhol Francisco de Goya, de modo a mostrar como o texto literário, através do diálogo interartístico questiona os limites da linguagem ficcional. Já em "A palavra-imagem e os elementos míticos na poética de Eugênio de Andrade e a correspondência entre poesia e pintura”, Amanda Aparecida Rodrigueiro busca demonstrar como os elementos naturais funcionam como eixo imagético dentro da obra eugeniana, em constante relação com artistas plásticos contemporâneos. Em seguida, Glaura Cardoso Vale discorre sobre o banal através das imagens de sowvenires, destacando a relação que Antunes estabelece com a música, o cinema e a pintura, no artigo "Considerações sobre o amor pelo banal, a literatura e as outras artes em António Lobo Antunes”. Em "Função histórica de caligrafia em Saramago”, José Leite Jr. estuda o paralelo explícito entre artes plásticas e a escrita no romance Manual de Pintura e Caligrafia, de José Saramago, demonstrando, através de uma análise semiótica, como a caligrafia resulta de uma síntese entre a pintura e a escrita. O artigo "Uma forma qualquer de silêncio: recusa e empenho na obra de Alberto Pimenta", de Carolina Anglada, por sua vez, estabelece um paradigma de silêncio na obra do artista contemporâneo, detalhando as possibilidades elocutórias decorridas do vazio, da interrupção e da morte em suas experiências poéticas, ensaísticas e performáticas. Por fim, Patrícia Resende Pereira, em "A descrição da guerra em Guernica por Carlos de Oliveira", demonstra, em leitura próxima ao poema, como este orienta-se diretamente pelo famoso painel de Pablo Picasso, transcriando-o literariamente.

A seção Vária traz quatro artigos que percorrem diversas paisagens e temas da cultura literária portuguesa. Ana Maria Domingues de Oliveira em "Malhas do poético nas Novas cartas portuguesas" trata da emergência do sentido de irmandade no livro de Maria Isabel Barreno, Maria Teresa Horta e Maria Velho da Costa. Em obra híbrida de gêneros e estilos, que embaralha a noção tradicional de autoria, Oliveira identifica pontos de encontro entre as vozes femininas e a figura literária de Sóror Mariana, inspiradora de protagonismo em um mundo opressor. O artigo "José Osório de Oliveira e suas reflexões sobre a 'moderna' literatura brasileira”, de Raquel S. Madanêlo Souza, analisa as contribuições 
do crítico português, autor da primeira história da literatura brasileira em Portugal, em 1939, para o debate, em voga na época, sobre a definição de uma literatura brasileira nacional e autônoma. Já "Animais e homens: uma dicotomia?", de Clarissa Moreira de Macedo, analisa o recurso da humanização dos animais representados em "Morgado", de Miguel Torga, o qual serve de contraponto simbólico à brutalização da maioria de seus personagens humanos. Com isso, chama-se a atenção para a necessidade do reaprendizado da natureza, dos valores e virtudes humanas. Por fim, o texto “"Este mundo, sem abrigo': o nomadismo na poesia de Jorge Gomes Miranda", de Julio Cesar Rodrigues Cattapan, investiga as deambulações do sujeito poético pelos espaços urbanos, em busca de laços de afeto, sentido e identidade. Tal movimento que se denomina "nomadismo" tem, segundo o autor, substituído a antiga flânerie na poesia contemporânea portuguesa.

Neste número trazemos ainda uma entrevista concedida pelo poeta surrealista Cruzeiro Seixas à pesquisadora brasileira Ana Cristina Joaquim, em dois momentos em outubro de 2013, nos quais Seixas discorre não apenas sobre sua obra e sua relação com o surrealismo português e francês, mas também sobre questões histórias e pessoais.

Em seguida, temos uma resenha de Isa Maria Marques de Oliveira do livro Fernando Pessoa: antologia poética, organizado por Cleonice Berardinelli e publicado pela Casa da Palavra em 2012, na qual a autora destaca sobretudo a acuidade do trabalho de Berardinelli e a contribuição que sua introdução e demais textos trazem à obra pessoana.

Cada um dos três poemas selecionados para a seção Poesia nos dá uma versão do tempo: estilhaçado em "Orquídea e Vasilisa: fragmento", poema amoroso e delicado de Adriana Zapparoli; aprofundado como matéria de reflexão em "Pequeno retrato do tempo", de Clarissa Macedo, que reúne "trapos" de um retrato vespertino vivo, ondulante, em que se descobre um sentido novo de interação; e, afinal, em "Como ser um negro", de Marcelo Ariel, no qual o tempo é fluxo infinito, somado à origem, para além da linearidade do tempo histórico e fragmentário do presente, e através dele, do tempo, ao desvelar o jogo dual das máscaras, os discursos epidérmicos dos papéis sociais e identitários, o poema vence as distâncias, encontra com o humano ilimitado, em busca do "intraduzível" de todos nós.

Na seção Ficção, a dimensão ecfrásica de "Moço à janela", de Andrea Silva, reivindica para a linguagem poética a desestruturação da cena central que, à moda de um quadro, surgiria tranquila e ordenada não fosse pela inclusão de uma "outra ordem das visibilidades", como diria Pedro Tamen, dada às emoções e às lembranças. Nesse viés experimental, também situamos seu segundo texto, "Espectros carnais". Por fim, igualmente como descrição de uma pintura em movimento, temos o texto "Um quadro negro de Goya", de Diego Felipe Pereira Noleto, que empresta do pintor espanhol alguns de seus temas sombrios para compor uma cena sórdida e decadente, povoada de personagens que se reencontram e revisitam locais do passado recente da juventude. A seção, como se vê, portanto, dialoga explicitamente com o tema deste número.

Desejamos a todos uma proveitosa leitura!

Bruno Anselmi Matangrano, Joana Souto Guimarães Araújo, Leonardo de Barros Sasaki, editores. 